\title{
Prevalence and drivers of human scabies among children and adolescents living and studying in Cameroonian boarding schools
}

\author{
Emmanuel Armand Kouotou ${ }^{1,2,3}$, Jobert Richie N. Nansseu ${ }^{2,4^{*}}$, Michèle K. Kouawa ${ }^{2}$ \\ and Anne-Cécile Zoung-Kanyi Bissek²
}

\begin{abstract}
Background: The dire lack of information concerning the epidemiology of human scabies in Cameroon, especially in school milieus brought us to undertake the present study which aimed to determine the prevalence and associated factors of scabies in Cameroonian boarding schools.

Methods: A cross-sectional study was conducted from February to March 2015 in four boarding schools in Yaoundé and Buea (Cameroon). Participants were students currently residing in one of the study sites, volunteering to participate in the study and whose parents or guardians had given their consent in this respect. The diagnosis was based on clinical assessment independently performed by two dermatologists.

Results: A total of 1,902 students were recruited ( $50.5 \%$ boys), with a mean age of $14.3 \pm 2.5$ years. Overall, 338 participants (17.8\%) were diagnosed with scabies. Age $\leq 15$ years, male sex, number of students in the school $>$ 500, no access to the school infirmary, sleeping with others, sharing beddings, clothes or toilet stuffs, pruritus in the close entourage and complaining of pruritus were significantly associated with the presence of mites in univariable logistic regression analyses. On the other hand, at least two baths per day, usage of soap for baths and finger nails always cut short appeared as protective factors. After multivariable analysis, male sex (adjusted OR (aOR) 2.06, $95 \%$ Cl: 1.40-3.01, $P<0.0001$ ), first cycle level of education (aOR 1.67, $95 \% \mathrm{Cl}: 1.02-2.71, P=0.040$ ), number of students per dormitory $\leq 10$ (aOR 6.99, $95 \%$ Cl: 3.34-14.71, $P<0.0001$ ), no access to the school infirmary (aOR 1.62, $95 \%$ Cl: $1.12-2.32, P=0.009$ ) and complaining of pruritus (aOR 93.37, $95 \% \mathrm{Cl}: 60.04-145.19, P<0.0001$ ) were the independent factors associated with scabies.
\end{abstract}

Conclusions: The prevalence of scabies was $17.8 \%$. The male sex, first cycle level of education, a number of students per dormitory $\leq 10$, no access to the school infirmary and complaining of pruritus were the independent factors significantly impacting the occurrence of scabies.

Keywords: Epidemiology, Human scabies, School, Cameroon

\section{Background}

Human scabies is an ectoparasitic infection of the skin caused by a mite, Sarcoptes scabiei var. hominis. It is ubiquitous, cosmopolitan, contagious and remains one of the most frequent skin diseases in resource-poor countries [1, 2]. The disease is transmitted through

\footnotetext{
* Correspondence: jobertrichie_nansseu@yahoo.fr

${ }^{2}$ Faculty of Medicine and Biomedical Sciences, University of Yaoundé I, Yaoundé, Cameroon

${ }^{4}$ Sickle Cell Disease Unit, Mother and Child Centre, Chantal Biya Foundation, Yaoundé, Cameroon

Full list of author information is available at the end of the article
}

direct and prolonged contact with an infected skin, or rarely by using contaminated personal objects $[1,2]$. It has a significant impact in terms of cost of treatment, absence at work or school and psychological repercussions $[3,4]$.

Scabies is a major public health problem in lowincome areas given its burden and complications, especially in the paediatric population $[1,5]$. In schoolchildren for instance, the infection often spreads quite rapidly, owing to their close contact and overcrowding within the schools $[1,2,6]$. Additionally, this health 
threat has been shown to negatively impact on learning [7]. Reports from a welfare home in Pulau Pinang (Malaysia), the Sivas orphanage (Turkey) and from Thai orphanages (Thailand) yielded a scabies prevalence of 31,33 and $87.3 \%$, respectively [8-10]. In an Islamic religious school (Bangladesh), Talukder et al. [11] observed prevalences of 61-62\%. Besides, in a study including 944 students of secondary boarding schools in Kuching (Sarawak, Malaysia), Yap et al. found 8.1 \% cases of human scabies [11].

In Africa, studies conducted in school milieus revealed a prevalence of scabies infestation of 4.4, 10.5, 4, 0.7 and 8.3 \% in Egypt, Nigeria, Mali, Malawi and Kenya, respectively $[6,7,12,13]$. However, there is a crucial lack of data regarding the burden of human scabies in school milieus in Cameroon, a sub-Saharan African country. To fill this gap, we undertook the present study, aiming to determine the prevalence and risk factors for human scabies in boarding schools in Cameroon.

\section{Methods}

\section{Ethical statement}

Prior to commencing this study, institutional authorisations were obtained from the authorities in charge of Secondary Education and from the administrative authorities of each study site. Besides, an ethical clearance was issued by the Ethical Review Board of the Faculty of Medicine and Biomedical Sciences of the University of Yaoundé I, Cameroon. Information leaflets and consent forms were sent to each student's parent or guardian, presenting all the aspects and procedures of the study, and we enrolled only students whose parents/guardians returned a signed consent form, hence authorising the investigators to include the child in the study. The present study did not interfere with the lessons at the study site, and the students who did not participate were neither reprimanded nor sanctioned.

\section{Study design, setting and participants}

From February to March 2015, we conducted a crosssectional study in four boarding schools in Cameroon. Of these, three were randomly chosen in Yaoundé (Centre Region of the country), namely the $\mathrm{Pi}$ and $\mathrm{Ju}$ (PNU) College, the Baptist High School (BHS) and the Christian Comprehensive Secondary School (CCSS). The fourth school, the Presbyterian Comprehensive Secondary School (PCSS), was randomly chosen among the boarding schools located in Buea (South-West region of Cameroon). Yaoundé and Buea were conveniently chosen, influenced by some facilities the investigators had in these towns, the study receiving neither funding nor sponsorship.

Participants were students, regardless of their level of education, currently residing in one of the study sites, volunteering to participate in the study and whose parents or guardians had given their consent in this respect. They were consecutively and exhaustively recruited during the study period. Students absent from the school when the investigators visited, or those refusing to participate were not included.

\section{Data collection}

Before recruitment, sensitisation sessions were organized by the investigators in each study site to inform the authorities and students of the various aspects of the study, emphasising on the huge advantages of taking part in it. Recruitments were performed at distance from lessons, in an adapted space prepared the day before, by a team of dermatologists, medical students and nurses.

Data were collected during an interview conducted by an investigator using a standardised and pretested questionnaire. Data collection comprised socio-demographic characteristics (age, sex, class attended and family size), history of pruritus (witnessed by the student or his/her entourage and the prevailing period) and frequency of baths and laundries.

Subsequently, a physical examination was independently undertaken by two experienced dermatologists. The diagnosis was ascertained, based on a clinical algorithm which has yielded a sensitivity of $100 \%$ and a specificity of $96.9 \%$ [14]. Accordingly, a student complaining of pruritus, on whom scabies lesions were notified at least at two specific body sites with or without history of pruritus in the close entourage was declared suffering from scabies. Dermoscopy and/or skin scrapings/microscopy were not available to confirm the diagnosis. Disagreements between the dermatologists were reconciled through discussion and consensus. Students found infected received antiscabies medications made of benzyl benzoate along with their entourage, given free of charge. Additionally, the bedding and laundry had to be disinfected.

\section{Statistical methods}

Data were analysed using SPSS version 20.0 (IBM, Chicago, Illinois, USA). Results are presented as frequency (percentage) or mean \pm standard deviation (SD) where appropriate. The Chi-square test or Fisher's exact test served for the comparison of qualitative variables. Student's $t$-test or equivalents were used for the comparison of quantitative variables. Odds ratios with $95 \%$ confidence intervals (CI) served to assess the factors impacting the presence of scabies; they were calculated with univariable and multivariable regression analyses while adjusting for confounding factors. All variables with $P<0.25$ in univariable analyses (and pertinent variables) were introduced in the multivariable model. The level of statistical significance was set at $P$-value $<0.05$. 


\section{Results}

Of the 2,235 students regularly registered in the four study sites, 152 were absent when the investigators visited and 181 refused to take part in the study. On the whole, 1,902 students were enrolled in this study, hence a participation of $85.1 \%$. Ages ranged from 9 to 22 years, with a mean of $14.3 \pm 2.5$ years. The most represented age group was $11-15$ years (65.8\%), followed by the group 16-20 years (30.8\%). There were 960 boys (50.5\%), hence a M/F sex ratio of $1.02 / 1$. We had 1,254 students $(65.9 \%)$ from the first cycle and 648 (34.1\%) from the second one. A total of 413 students (21.7\%) complained of pruritus, mainly at night and leading to insomnias among 278 students (67.3\%).

We diagnosed 338 participants (17.8\%) with human scabies among whom 223 boys (66.0\%). There were significantly more infected boys than girls $(23.3 \%$ vs $12.2 \% ; \chi^{2}=39.521, d f=1, P<0.0001$; Table 1$)$. Ages of these infected students ranged between 9 and 20 years, with a mean of $13.5 \pm 2.3$ years. Students with scabies were younger than those without (mean $13.5 \mathrm{vs}$ 14.5 years; $t$-test, $t=6.585, d f=1900, P<0.0001)$; they were from boarding schools with significantly higher number of registered students (mean 914.3 vs 732.7 students; $t$-test, $t=9.554, d f=571.069, \quad P<0.0001)$. The number of students staying in the same dormitory was lower among students with scabies compared to those without (mean 25.8 vs 32.0 students; $\mathrm{t}$ - test, $t=7.191$, $d f=571.069, \quad P<0.0001)$, as well as the number of students sharing the same toilet (mean 52.3 vs 63.1 students; $t$-test, $t=2.122, d f=109.382, P=0.036)$.

Table 1 displays the univariable and multivariable regression analyses. In univariable analyses, age $\leq 15$ years, male sex, number of students in the school $>500$, no access to the school infirmary, sleeping with others, sharing beddings, clothes or toilet stuffs, pruritus in the close entourage and complaining of pruritus were significantly associated with the presence of mites. On the other hand, at least two baths per day, usage of soap for baths and finger nails always cut short appeared as protective factors (Table 1). After multivariable analysis, male sex (adjusted OR (aOR) 2.06, 95 \% CI: 1.40-3.01; $P<0.0001$ ), first cycle level of education (aOR 1.67, $95 \%$ CI: $1.02-2.71 ; P=0.040)$, number of students per dormitory $\leq 10$ (aOR 6.99, $95 \%$ CI: 3.34-14.71; $P<0.0001$ ), no access to the school infirmary (aOR 1.62, $95 \%$ CI: $1.12-$ 2.32; $P=0.009$ ) and complaining of pruritus (aOR 93.37, 95 \% CI: 60.04-145.19; $P<0.0001)$ were the independent factors associated with scabies.

Concerning the sites of lesions, interdigital spaces (61.2\%), wrists (54.4\%), buttocks (48.5\%) and elbows $(39.1 \%)$ were the main sites (Table 2). Lesions were diffused in $13.0 \%$ of cases. Moreover, papules $(75.4 \%)$ and scratch marks $(66.3 \%)$ were the most recorded non- specific lesions whereas pearled vesicles (43.2\%) and scabious nodules $(33.1 \%)$ were the prevailing specific lesions of the disease (Table 2).

\section{Discussion}

This study conducted in four boarding schools in Cameroon identified $17.8 \%$ cases of human scabies. The male sex, first cycle level of education, a number of students per dormitory $\leq 10$, no access to the school infirmary and complaining of pruritus were the independent factors significantly impacting the occurrence of scabies. Sites and types of infection resembled what was observed in a previous study [15].

The prevalence of scabies in this study $(17.8 \%)$ is higher than what has been reported from Malaysian secondary boarding schools $(8.1 \%)$ and some African school milieus, between 0.7 and $13 \%[6,7,12,16]$. It is comparable to the $18.5 \%$ found by Pasay et al. [17], but is lower than what was witnessed among children in a Malaysian welfare home (31 \%), in a Turkish orphanage (33\%), in a Bangladesh Islamic religious school (61-62 \%), in a Sierra Leone displacement camp (67\%) and in Thailand orphanages $(87.5 \%)[8-10,18,19]$. Likewise, high rates of scabies infestation have been observed in prisons, around 41$57 \%[20,21]$. High rates of scabies are usually found in communities and milieus where overcrowding and poverty are highly prevalent $[1,2]$, perhaps explaining the discrepancies between our results and other ones.

Indeed, although the number of students in the school > 500 was a significant risk factor in univariable analysis, it became nonsignificant in the multivariable model, may be inferring that these schools where not too congested to lead to the spreading of the infection. It is true however that the result in the multivariable model could have been different with a different cut-off point; the 500-student cut-off was chosen arbitrarily. A number of students per dormitory $\leq 10$ was also associated with scabies, a paradoxical and troubling finding as we would have expected the contrary. Nonetheless, we observed that these students were more prone to bathe less than twice daily compared to their counterparts $(P=0.019)$, showing perhaps that they had a poorer personal hygiene which can therefore explain the results.

Being younger ( $\leq 15$ years old) was also a risk factor in univariable analysis but not in the multivariable one, compared with first cycle level of education which remained significant in the multivariable model. Considering that the spreading of human scabies is linked with poor personal hygiene $[1,2]$, it is possible that the younger students, who are of lower educational level than their counterparts, are less aware of personal hygiene rules to adopt especially when living with others, being therefore more prone to be infected. We observed in fact that younger students were significantly more prone 
Table 1 Comparison between students with and without scabies, and univariable and multivariable logistic regression analyses

\begin{tabular}{|c|c|c|c|c|c|c|}
\hline \multirow[t]{2}{*}{ Variable } & Without scabies $(n=1,564)$ & With scabies $(n=338)$ & OR (95 \% Cl) & $P$-value & aOR $(95 \% C l)^{\mathrm{a}}$ & $P$-value \\
\hline & Number (\%) & \multicolumn{5}{|l|}{ Number (\%) } \\
\hline \multicolumn{7}{|l|}{ Age group (years) } \\
\hline$\leq 15$ & $1,039(79.6)$ & $267(20.4)$ & $1.90(1.43-2.52)$ & $<0.0001^{*}$ & $1.11(0.65-0.87)$ & 0.708 \\
\hline$>15$ & $525(88.1)$ & $71(11.9)$ & 1 & & 1 & \\
\hline \multicolumn{7}{|l|}{ Sex } \\
\hline Females & $827(87.8)$ & $115(12.2)$ & 1 & & 1 & \\
\hline Males & 737 (76.8) & $223(23.2)$ & $2.18(1.70-2.78)$ & $<0.0001^{*}$ & $2.06(1.40-3.01)$ & $<0.0001^{*}$ \\
\hline \multicolumn{7}{|l|}{ Level of education } \\
\hline First cycle & $1,027(81.9)$ & $227(18.1)$ & $1.07(0.83-1.37)$ & 0.599 & $1.67(1.02-2.71)$ & $0.040^{*}$ \\
\hline Second cycle & $537(82.9)$ & $111(17.1)$ & 1 & & 1 & \\
\hline \multicolumn{7}{|c|}{ Number of students in the school } \\
\hline$\leq 500$ & $438(90.9)$ & $44(9.1)$ & 1 & & 1 & \\
\hline$>500$ & $1,126(79.3)$ & $294(20.7)$ & $2.60(1.86-3.64)$ & $<0.0001^{*}$ & $1.65(0.99-2.74)$ & 0.054 \\
\hline \multicolumn{7}{|c|}{ Number of students using the same toilet } \\
\hline$\leq 10$ & $25(86.2)$ & $4(13.8)$ & 1 & & & \\
\hline$>10$ & $1,539(82.2)$ & $334(17.8)$ & $1.36(0.47-3.92)$ & 0.574 & / & / \\
\hline \multicolumn{7}{|c|}{ Number of students per dormitory } \\
\hline$\leq 10$ & $84(77.8)$ & $24(22.2)$ & $1.35(0.86-2.16)$ & 0.214 & $6.99(3.34-14.71)$ & $<0.0001^{*}$ \\
\hline$>10$ & $1,480(82.5)$ & $314(17.5)$ & 1 & & 1 & \\
\hline \multicolumn{7}{|l|}{ Number of baths } \\
\hline At least twice daily & $73(61.3)$ & $46(38.7)$ & $0.31(0.21-0.46)$ & $<0.0001^{*}$ & $0.52(0.25-1.07)$ & 0.076 \\
\hline Less than twice daily & $1,491(83.6)$ & $292(16.4)$ & 1 & & 1 & \\
\hline \multicolumn{7}{|l|}{ Access to infirmary } \\
\hline No & $772(80.3)$ & $189(19.7)$ & $1.30(1.03-1.65)$ & $0.029^{*}$ & $1.62(1.12-2.32)$ & $0.009^{*}$ \\
\hline Yes & $792(84.2)$ & $149(15.8)$ & 1 & & & \\
\hline \multicolumn{7}{|l|}{ Sleeping with others } \\
\hline No & $1,494(83.6)$ & $293(16.4)$ & 1 & & 1 & \\
\hline Yes & $70(60.9)$ & $45(39.1)$ & $3.28(2.21-4.87)$ & $<0.0001^{*}$ & $1.29(0.69-2.41)$ & 0.433 \\
\hline \multicolumn{7}{|c|}{ Sharing of beddings, clothes or toilet stuffs } \\
\hline No & $677(85.4)$ & $116(14.6)$ & 1 & & 1 & \\
\hline Yes & $887(80.0)$ & $222(20.0)$ & $1.46(1.14-1.87)$ & $0.002^{*}$ & $1.08(0.73-1.59)$ & 0.700 \\
\hline \multicolumn{7}{|l|}{ Usage of soap for baths } \\
\hline No & $150(65.2)$ & $80(34.8)$ & 1 & & 1 & \\
\hline Yes & $1,414(84.6)$ & $258(15.4)$ & $0.34(0.25-0.46)$ & $<0.0001^{*}$ & $0.76(0.44-1.32)$ & 0.329 \\
\hline \multicolumn{7}{|c|}{ Finger nails always cut short } \\
\hline No & $352(74.1)$ & $123(25.9)$ & 1 & & 1 & \\
\hline Yes & $1,212(84.9)$ & $215(15.1)$ & $0.51(0.40-0.65)$ & $<0.0001^{*}$ & $0.84(0.55-1.30)$ & 0.439 \\
\hline \multicolumn{7}{|c|}{ Ironing of clothes and bedding } \\
\hline No & $1,220(81.8)$ & $272(18.2)$ & 1 & & & \\
\hline Yes & $344(83.9)$ & $66(16.1)$ & $0.86(0.64-1.16)$ & 0.317 & / & / \\
\hline \multicolumn{7}{|c|}{ Pruritus in the close entourage } \\
\hline No & $999(90.2)$ & $108(9.8)$ & 1 & & 1 & \\
\hline Yes & $565(71.1)$ & $230(28.9)$ & $3.77(2.94-4.84)$ & $<0.0001^{*}$ & $1.30(0.87-1.93)$ & 0.196 \\
\hline
\end{tabular}


Table 1 Comparison between students with and without scabies, and univariable and multivariable logistic regression analyses (Continued)

Complaining of pruritus

No

$1,441(96.8)$

48 (3.2)

1

Yes

123 (29.8)

$290(70.2)$

$70.78(49.55-101.11)<0.0001^{*} 93.37(60.04-145.19)$

$<0.0001$

Abbreviations: $a O R$ adjusted odds ratio, $\mathrm{Cl}$ confidence interval, $O R$ odds ratio

${ }^{a}$ All variables with $P<0.25$ in univariable analyses (plus level of education) were introduced in the multivariable model. The coefficient of determination of this model was $R^{2}$ of McFadden $=0.520(P<0.0001)$

${ }^{*} P$-value $<0.05$

to share their beddings or clothes with others, sleep with others and have a history of pruritus in their close entourage than the elders (all $P$-values $<0.0001$ ).

The male sex was a risk factor for scabies infestation, a finding differing from Hegab et al's report in Egypt where there was no difference between males and females [6]. We noticed that more boys used to sleep with others $(P=0.001)$, more had a history of pruritus in their close entourage $(P=0.006)$, less used soap for bathing $(P<0.0001)$ and less had their finger nails always cut short $(P<0.0001)$ than girls. These observations may explain why the male sex was a risk factor for scabies in this study. Sleeping with others had already been identified as a risk factor for scabies infestation [6,22], as well as sharing of clothes with others [6]. However, these variables which were significant in univariable analyses became nonsignificant in our multivariable model.

Table 2 Sites and types of lesions

\begin{tabular}{lll}
\hline Characteristic & & Number (\%) \\
\hline Type of lesions & & \\
Non-specific lesions & Hyperkeratosic and crusty lesions & $129(38.2)$ \\
& Papules & $255(75.4)$ \\
& Pustules & $26(7.7)$ \\
& Scratch marks & $224(66.3)$ \\
Specific lesions & Pearled vesicles & $146(43.2)$ \\
& Scabious nodules & $112(33.1)$ \\
& Foot & $54(16.0)$ \\
& Axillary creases & $83(24.6)$ \\
& Interdigital spaces & $207(61.2)$ \\
& Wrists & $184(54.4)$ \\
& Elbows & $132(39.1)$ \\
& Buttocks & $164(48.5)$ \\
& Anterior face of thighs & $109(32.3)$ \\
& Glans & $31(9.2)$ \\
& Breasts & $9(2.7)$ \\
& Anterior armholes & $116(34.3)$ \\
& Posterior armholes & $90(26.6)$ \\
& Inguinal creases & $85(25.2)$ \\
& Diffused & $44(13.0)$ \\
\hline
\end{tabular}

Lack of accessibility to the school infirmary was independently linked with scabies (aOR 1.62). In fact, considering the high contagiousness of human scabies which is transmitted by contact with an infected skin $[1,2]$, it is clear that if a student is infected and has no access to the infirmary to consult and be treated, he/she will be a continuous point of spreading of the disease. Moreover and unsurprisingly, students complaining of pruritus had a 93.4-fold increased risk of being diagnosed with scabies, given the highly itching character of this skin infection. The itching can become very intense and uncomfortable, so much so that it may affect the quality of life of the individuals affected [4]. We noticed in this concern that a significant number of infected students complaining of pruritus were experiencing insomnias in comparison to their counterparts without scabies $(P<$ 0.0001). This may negatively impact the school performances of the student [7]. We need further studies to thoroughly investigate the quality of life and negative effects of scabies in students and in the general population.

Some limitations of our study are to be mentioned. First, dermoscopy and/or skin scrapings/microscopy were not available to confirm the presence of mites, although they are operator-dependent and have relatively low sensitivities around 90-91\% [23, 24]. Our diagnosis was essentially based on clinical assessment independently conducted by two dermatologists, on the basis that clinical assessment of human scabies has been shown with good sensitivity and specificity: 100 and $96.9 \%$, respectively [14]. Secondly, the cross-sectional design of this study precludes us from affirming with conviction that the predictors identified are really independent risk factors for scabies in these boarding schools. Thirdly, our findings might not be generalised to the entire population of Cameroon boarding students given that we worked only in four schools; however, these study sites were randomly chosen in the Centre and SouthWest regions of the country.

\section{Conclusion}

We found from this study of 1,902 students recruited in four boarding schools in Cameroon that the prevalence of human scabies was $17.8 \%$. The male sex, first cycle level of education, a number of students per dormitory $\leq 10$, no 
access to the school infirmary and complaining of pruritus were the independent factors significantly impacting the occurrence of scabies. Strong measures should be taken to ameliorate accessibility of students to school infirmaries and provide these facilities with enough resources to take care of children health issues at school. Additionally, personal hygiene rules should be taught to students, with special emphasis among boys and the younger students. More studies to better elucidate all the factors driving the occurrence of scabies and its impact on quality of life of the children affectedare warranted in our contexts.

\section{Abbreviations}

aOR, adjusted odds ratio; $\mathrm{OR}$, odds ratio; $\mathrm{SD}$, standard deviation

\section{Acknowledgments}

The authors are most grateful to all the administrative authorities of the schools visited and to the students who have kindly accepted to take part in this study. They also acknowledge Dr Sandra Ayuk Tatah for the substantial time she has taken to critically review and revise the manuscript.

\section{Funding}

This study benefited from no external source of funding; it was only sponsored by the authors.

\section{Availability of data and materials}

Data supporting the conclusions of this article are included within the article. The Ethical Review Board of the Faculty of Medicine and Biomedical Sciences of the University of Yaoundé I did not authorize us to make the raw data available.

\section{Competing interests}

The authors declare that they have no competing interests.

\section{Authors' contributions}

EAK and MKK conceived and designed the study, and collected the data. JRNN and MKK analyzed and interpreted the data. JRNN, EAK and MKK drafted and reviewed the manuscript. ACZKB participated in study conception and design, and critically reviewed and revised the manuscript. All authors read and approved the final manuscript.

\section{Ethics approval and consent to participate}

An ethical clearance was issued by the Ethical Review Board of the Faculty of Medicine and Biomedical Sciences of the University of Yaoundé I, Cameroon. We enrolled only students whose parents/guardians returned a signed consent form, hence authorizing the investigators to include the child in the study.

\section{Author details}

'Biyem-Assi District Hospital, Yaoundé, Cameroon. ${ }^{2}$ Faculty of Medicine and Biomedical Sciences, University of Yaoundé I, Yaoundé, Cameroon. ${ }^{3}$ Yaoundé General Hospital, Yaoundé, Cameroon. ${ }^{4}$ Sickle Cell Disease Unit, Mother and Child Centre, Chantal Biya Foundation, Yaoundé, Cameroon.

Received: 29 April 2016 Accepted: 10 July 2016

Published online: 19 July 2016

\section{References}

1. Andrews RM, McCarthy J, Carapetis JR, Currie BJ. Skin disorders, including pyoderma, scabies, and tinea infections. Pediatr Clin North Am. 2009;56(6): $1421-40$.

2. Heukelbach J, Feldmeier $\mathrm{H}$. Ectoparasites - the underestimated realm. Lancet. 2004:363(9412):889-91.

3. Clore ER, Longyear LA. Comprehensive pediculosis screening programs for elementary schools. J Sch Health. 1990;60(5):212-4.

4. Abasiubong F, Akpan N, Upong DI, Umanah I, Udoh SB. Quality of life in patients with skin diseases in Uyo, a community in South-South Nigeria. Adv Trop Med Pub Health Int. 2011;1(2):55-65.
5. Downs AM, Harvey I, Kennedy CT. The epidemiology of head lice and scabies in the UK. Epidemiol Infect. 1999:122(3):471-7.

6. Hegab DS, Kato AM, Kabbash IA, Dabish GM. Scabies among primary schoolchildren in Egypt: sociomedical environmental study in Kafr El-Sheikh administrative area. Clin Cosmet Investig Dermatol. 2015;8:105-11.

7. Kalu El, Wagbatsoma V, Ogbaini-Emovon E, Nwadike VU, Ojide CK. Age and sex prevalence of infectious dermatoses among primary school children in a rural south-eastern Nigerian community. Pan Afr Med J. 2015;20:182.

8. Muhammad Zayyid M, Saidatul Saadah R, Adil AR, Rohela M, Jamaiah I. Prevalence of scabies and head lice among children in a welfare home in Pulau Pinang, Malaysia. Trop Biomed. 2010;27(3):442-46.

9. Oztürkcan S, Ozçelik S, Saygi G, Ozçelik S. Spread of scabies and pediculus humanus among the children at Sivas orphanage. Indian Pediatr. 1994;31(2):210-13.

10. Pruksachatkunakorn C, Wongthanee A, Kasiwat V. Scabies in Thai orphanages. Pediatr Int Off J Jpn Pediatr Soc. 2003;45(6):724-7.

11. Talukder K, Talukder MQ, Farooque MG, Khairul M, Sharmin F, Jerin I, et al. Controlling scabies in madrasahs (Islamic religious schools) in Bangladesh. Public Health. 2013;127(1):83-91.

12. Yap FB, Elena EM, Pubalan M. Prevalence of scabies and head lice among students of secondary boarding schools in Kuching, Sarawak, Malaysia. Pediatr Infect Dis J. 2010;29(7):682-3.

13. Landwehr D, Keita SM, Pönnighaus JM, Tounkara C. Epidemiologic aspects of scabies in Mali, Malawi, and Cambodia. Int I Dermatol. 1998:37(8):588-90.

14. Schmeller W, Dzikus A. Skin diseases in children in rural Kenya: long-term results of a dermatology project within the primary health care system. Br J Dermatol. 2001;144(1):118-24.

15. Mahé A, Faye $\mathrm{O}, \mathrm{N}^{\prime}$ Diaye HT, Ly F, Konaré $H$, Kéita $S$, et al. Definition of an algorithm for the management of common skin diseases at primary health care level in sub-Saharan Africa. Trans R Soc Trop Med Hyg. 2005;99(1):39-47.

16. Kouotou EA, Nansseu JR, Sieleunou I, Defo D, Bissek AC, Ndam EC. Features of human scabies in resource-limited settings: the Cameroon case. BMC Dermatol. 2015;15:12.

17. Traoré A, Ouédraogo SM, Sanou I, Kouéta F, Kyelem N, Konaté l, et al. Epidemiological features of human mite infestation in schools in the town of Ouagadougou (Burkina Faso) [in French]. Nouv Dermatol. 2000:19:334-7.

18. Pasay C, Walton S, Fischer K, Holt D, McCarthy J. PCR-based assay to survey for knockdown resistance to pyrethroid acaricides in human scabies mites (Sarcoptes scabiei var. hominis). Am J Trop Med Hyg. 2006;74:649-57.

19. Terry BC, Kanjah F, Sahr F, Kortequee S, Dukulay I, Gbakima AA. Sarcoptes scabiei infestation among children in a displacement camp in Sierra Leone. Public Health. 2001;115(3):208-11.

20. Poudat A, Nasirian H. Prevalence of pediculosis and scabies in the prisoners of Bandar Abbas, Hormozgan province, Iran. Pak J Biol Sci. 2007:10(21):3967-9.

21. Kouotou EA, Sieleunou I, Defo D, Nansseu NJR, Atenkeng Apasew H, Moyou Somo R, et al. Skin diseases among sub-Saharan African prisoners: the Cameroonian profile. IJCDR. 2014;2:701.

22. Kouotou EA, Defo D, Sieleunou I, Ndikontar Kwinji R, Mukwelle K, Essama J, et al. La gale humaine : profil sociodémographique, distribution lésionnelle et types de lésions. Health Sci Dis. 2013;14(3):1-6.

23. Dupuy A, Dehen L, Bourrat E, Lacroix C, Benderdouche M, Dubertret L, et al. Accuracy of standard dermoscopy for diagnosing scabies. J Am Acad Dermatol. 2007:56(1):53-62.

24. Leung V, Miller M. Detection of scabies: a systematic review of diagnostic methods. Can J Infect Dis Med Microbiol. 2011:22(4):143-6. 